\title{
Nucleolus as an emerging hub in maintenance of genome stability and cancer pathogenesis
}

\author{
Mikael S. Lindström ${ }^{1} \cdot$ Deana Jurada $^{2,3} \cdot$ Sladana Bursac $^{2,3} \cdot$ Ines Orsolic ${ }^{2,3} \cdot$ Jiri Bartek $^{1,4} \cdot$ Sinisa Volarevic $^{2,3}$
}

Received: 10 October 2017 / Revised: 15 November 2017 / Accepted: 15 November 2017 / Published online: 12 February 2018

(c) The Author(s) 2018. This article is published with open access

\begin{abstract}
The nucleolus is the major site for synthesis of ribosomes, complex molecular machines that are responsible for protein synthesis. A wealth of research over the past 20 years has clearly indicated that both quantitative and qualitative alterations in ribosome biogenesis can drive the malignant phenotype via dysregulation of protein synthesis. However, numerous recent proteomic, genomic, and functional studies have implicated the nucleolus in the regulation of processes that are unrelated to ribosome biogenesis, including DNA-damage response, maintenance of genome stability and its spatial organization, epigenetic regulation, cell-cycle control, stress responses, senescence, global gene expression, as well as assembly or maturation of various ribonucleoprotein particles. In this review, the focus will be on features of rDNA genes, which make them highly vulnerable to DNA damage and intra- and interchromosomal recombination as well as built-in mechanisms that prevent and repair rDNA damage, and how dysregulation of this interplay affects genome-wide DNA stability, gene expression and the balance between euchromatin and heterochromatin. We will also present the most recent insights into how malfunction of these cellular processes may be a central driving force of human malignancies, and propose a promising new therapeutic approach for the treatment of cancer.
\end{abstract}

\section{Introduction}

The nucleolus is the most prominent nuclear substructure involved in production of ribosomes, large and complex ribonucleoprotein machines responsible for translation of mRNAs into proteins (Fig. 1a) [1]. The human $80 \mathrm{~S}$ ribosome is composed of a $40 \mathrm{~S}$ subunit consisting of $18 \mathrm{~S}$ ribosomal RNA (rRNA) and 33 distinct ribosomal proteins

\section{Jiri Bartek}

jb@cancer.dk

$\triangle$ Sinisa Volarevic

sinisa.volarevic@medri.uniri.hr

1 Division of Genome Biology, Department of Medical Biochemistry and Biophysics, Karolinska Institutet, Stockholm, Sweden

2 Department of Molecular Medicine and Biotechnology, School of Medicine, University of Rijeka, Rijeka, Croatia

3 Scientific Center of Excellence for Reproductive and Regenerative Medicine, University of Rijeka, Rijeka, Croatia

4 The Danish Cancer Society Research Centre, Copenhagen, Denmark
(RPs), and a $60 \mathrm{~S}$ subunit containing $5 \mathrm{~S}, 5.8 \mathrm{~S}$, and $28 \mathrm{~S}$ rRNAs and 47 distinct RPs [2,3]. Nucleoli form around the nucleolar organizer regions (NORs) on acrocentric chromosomes 13, 14, 15, 21, and 22 that contain clusters of 300 ribosomal DNA gene repeats (rDNA) mostly arranged in a head-to-tail manner, although inverted rDNA repeats or palindromes are also present [4]. The number of rDNA repeat units varies significantly across the human population, suggesting that these loci are susceptible to intrinsic recombinational instability [5]. The rDNA clusters consist of modules of $\sim 13 \mathrm{~kb}$ transcribed by RNA polymerase I (Pol I) into the $47 \mathrm{~S}$ pre-rRNA, and an intergenic spacer (IGS) of $\sim 30 \mathrm{~kb}$ (Fig. 1b). The $47 \mathrm{~S}$ pre-rRNA transcript is processed into $18 \mathrm{~S}, 5.8 \mathrm{~S}$, and $28 \mathrm{~S}$ rRNAs. The IGS contains: spacer promoters, repetitive enhancer elements, the $47 \mathrm{~S}$ pre-RNA promoter, origins of DNA replication, terminator elements $(\mathrm{T})$ downstream and upstream of the prerRNA transcription unit that can bind transcription termination factor (TTF-I), replication fork barriers (RFBs), tandem repeats and non-coding RNA genes transcribed by Pol II under certain stress conditions (Fig. 1b) [6]. DNA sequences proximal and distal to rDNA arrays are highly conserved among the five acrocentric chromosomes. Whereas proximal sequences, termed proximal junctions 

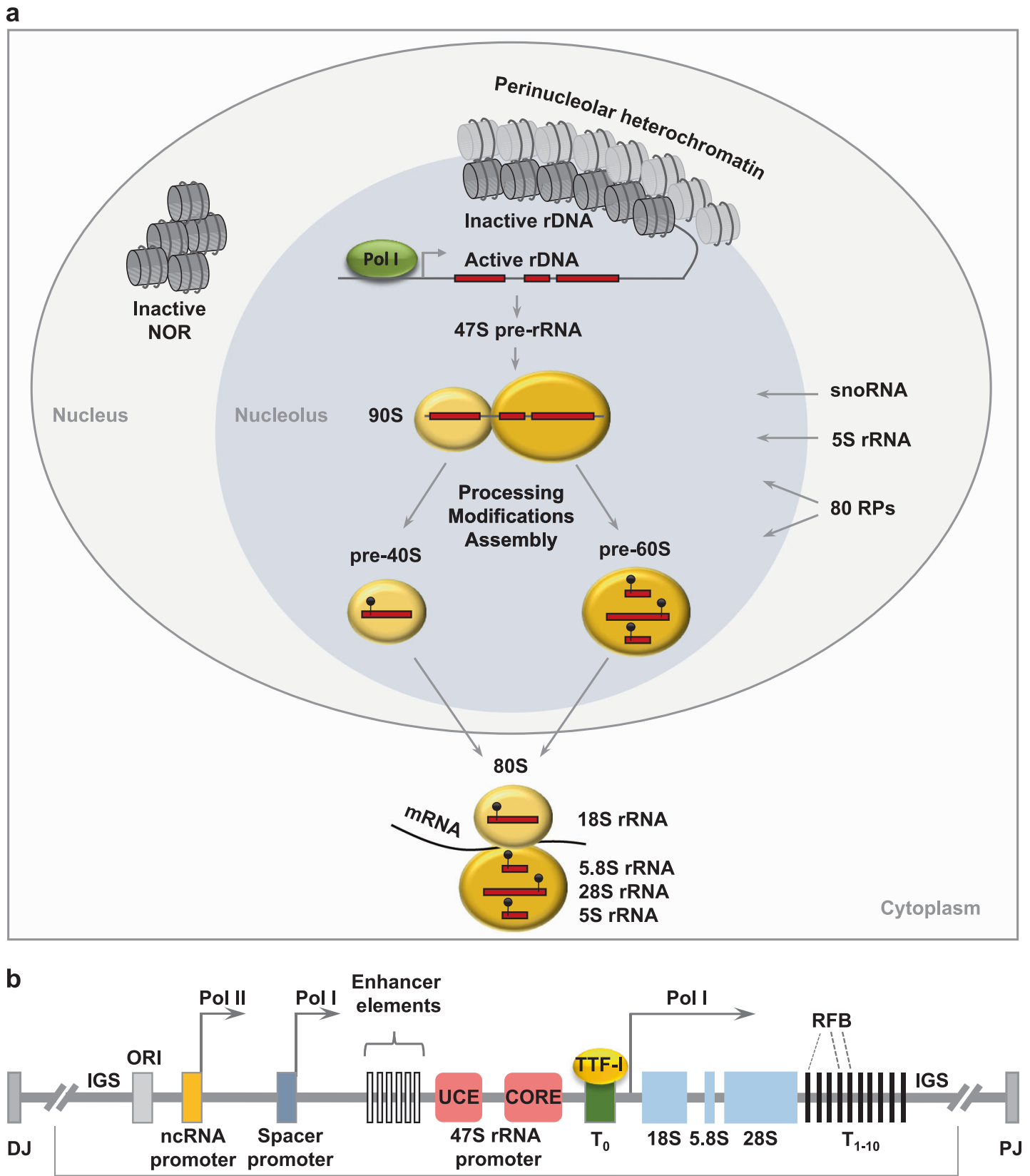

One of multiple repeats

Fig. 1 Nucleolus and rDNA genes. a Intranucleolar heterochromatic inactive rDNA repeats are tightly connected with perinucleolar heterochromatin, whereas euchromatic active rDNA genes are transcribed into the $47 \mathrm{~S}$ pre-rRNA by Pol I. The $47 \mathrm{~S}$ pre-rRNA is cotranscriptionally assembled into the $90 \mathrm{~S}$ processome with RPs and $5 \mathrm{~S}$ rRNA and modified by $\sim 200$ snoRNPs. Following cleavage of the pre-rRNA, the $90 \mathrm{~S}$ processome separates into a pre-60S subunit and a pre-40S subunit that largely follow independent maturation pathways

(PJ) are segmentally duplicated and resemble the regions flanking centromeres on other chromosomes, the distal junctions (DJ) are unique to the five acrocentric chromosomes and contain a large inverted repeat and 48-bp satellite repeats (Fig. 1b) [7]. Each arm of the inverted repeat can be in the nucleolus, the nucleoplasm and the cytoplasm. Modifications of rRNA are indicated with lollipops. b Schematic diagram of the rDNA array. Shown are coding regions for $18 \mathrm{~S}, 5.8 \mathrm{~S}$, and $28 \mathrm{~S}$ rRNA as well as IGS with the rDNA core promoter and upstream control element (UCE), enhancers, spacer promoter, and Pol I promoter, ORIs as well as T0 that binds TTF-I and T1, T4, and T5 that act as RFBs. DJ and PJ sequences that flank the rDNA array are indicated

transcribed by Pol II into long non-coding RNAs implicated in chromatin regulation [7].

In proliferating cells, the nucleolus disassembles during prophase and begins to reassemble in telophase [1]. Upstream binding factor (UBF)-dependent mitotic 
bookmarking of NORs is responsible for the open chromatin state, visible as achromatic gaps on DAPI-stained metaphase chromosomes and the establishment of a transcriptionally active state essential for post-mitotic nucleolar formation [8]. Conversely, NORs unbound by UBF possess epigenetic features characteristic of constitutive heterochromatin; they are transcriptionally incompetent and not associated with the nucleoli (Fig. 1a) [4]. Importantly, both transcriptionally active (euchromatic) and inactive (heterochromatic) rDNA repeats are present in "active" NORs associated with the nucleoli (Fig. 1a) [4]. Transcriptionally active rDNA genes represent $\sim 50 \%$ of all rDNA repeats and localize at the surface of the so-called fibrillar center where they are transcribed by Pol I into the $47 \mathrm{~S}$ pre-rRNA. Inactive rDNA repeats form intranucleolar heterochromatin [9]. The ratio between active and inactive rDNA genes is regulated through recruitment of either Cockayne syndrome B protein (CSB) or nucleolar remodeling complex (NoRC) to TTF-I bound to the promoter-proximal terminator $\mathrm{T}_{0}$ [10]. Whereas the CSB-loaded TTF-I recruits histone methyltransferase G9a and HP1 $\gamma$, leading to the establishment and maintenance of transcriptionally active state, binding of NoRC subunit TIP5 (TTF-I-interacting protein 5) to TTF-I leads to recruitment of enzymes that induce $\mathrm{CpG}$ DNA methylation and heterochromatic histone modifications on rDNA. However, the molecular mechanisms responsible for the differential recruitment of CBS or NoRC to TTF-I at $\mathrm{T}_{0}$ remain unknown [10]. Intranucleolar heterochromatin containing inactive rDNA repeats is tightly connected with a shell of heterochromatin surrounding the nucleolus, known as perinucleolar heterochromatin (Fig. 1a) [9]. The establishment and maintenance of perinucleolar heterochromatin is also regulated by NoRC, suggesting functional interdependence between these two heterochromatic domains [11], partly mediated by the DJ sequences embedded in adjacent perinucleolar chromatin to anchor the NORs to nucleoli [7].

Ribosome biogenesis is the most energy consuming process in human cells [12]. rDNA genes are the most actively transcribed genes, collectively accounting for more than half of total transcription in proliferating cells [13]. The production of the $47 \mathrm{~S}$ pre-rRNA was thought to be exclusively controlled by changing the rate of Pol I transcription. However, recent evidence indicates that epigenetic mechanisms also regulate this process by altering the ratio of active and inactive rDNA genes in response to specific cues $[6,14,15]$. The $47 \mathrm{~S}$ pre-rRNA is co-transcriptionally assembled into the $90 \mathrm{~S}$ processome, with numerous RPs and $5 \mathrm{~S}$ rRNA synthesized by Pol III, where it is subjected to ribose 2'-O-methylation and pseudouridylation, folding and processing steps depending on $\sim 200$ snoRNAs (Fig. 1a) $[16,17]$. Following cleavage within the internal transcribed spacer the $90 \mathrm{~S}$ processomes are separated into pre-40S and
pre-60S ribosomal subunits that follow largely independent maturation pathways in the nucleolus, the nucleoplasm and the cytoplasm (Fig. 1a) [18]. Most research on the nucleolus has focused on understanding ribosome biogenesis and the impact of altered ribosome biogenesis on the development of human diseases, notably ribosomopathies and cancer [19]. However, proteomic studies have identified some 4500 nucleolar proteins, mostly participating in processes unrelated to ribosome biogenesis [20]. Based on results of these and functional studies, the nucleolus has been implicated in the regulation of additional cellular processes: genome integrity maintenance, epigenetic control, cell-cycle regulation, diverse stress responses, cellular senescence, genomic organization, nuclear architecture, and maturation, assembly, and export of the signal recognition particle, telomerase RNP and processing of precursor transfer RNAs $[19,21]$. Collectively these studies demonstrate that the nucleolus performs many more functions than originally appreciated.

Several features make rDNA genes highly vulnerable to DNA damage and intra- and interchromosomal recombination, including high transcription rate, challenging DNA replication, repetitive nature, and presence in clusters on five different chromosomes [4, 22]. This review will discuss rDNA damage and repair mechanisms, and how dysregulation of these processes affects genome-wide DNA stability, gene expression and the balance between euchromatin and heterochromatin. We will also review the recent advances in understanding how malfunction of these processes may contribute to malignancy, and opportunities to exploit this emerging knowledge for improvements of anticancer treatments.

\section{Systematic proteomic and genomic studies implicate the nucleolus in promoting genome stability}

Based on studies of the nucleolar proteome and the human protein atlas database, Ogawa and Baserga assembled a list of 166 DNA repair proteins that localize to the nucleolus [23]. However, whether the nucleolus is just a storage depot for DNA-damage response (DDR) proteins that operate in the nucleus or they indeed play some specific nucleolar roles, remains unclear. A number of DDR proteins accumulate in the intranucleolar body (INB) and nucleolar cap structures upon DNA damage, suggesting that these structures provide a platform for recruitment of specific factors that sense and repair rDNA damage in the nucleolus [24]. Furthermore, genetic screens to identify human ribosome biogenesis factors revealed that a subset of these factors are co-classified as DDR proteins [25-27]. Moreover, a mass spectrometry analysis of proteins phosphorylated in 
response to DNA damage by ataxia-telangiectasia-mutated (ATM) and ataxia telangiectasia and Rad3-related (ATR) kinases revealed 700 target proteins, 98 of which are nucleolar proteins involved in various aspects of ribosome biogenesis, ribosome function and epigenetic regulation of rDNA genes, thus further supporting the notion that the nucleolus is an important hub of the DDR [28, 29]. A recent genetic screen in yeast revealed that almost $15 \%$ of 4876 non-essential genes, most of which have not been linked to nucleolar functions so far, are required for the maintenance of rDNA stability, revealing an unexpected complexity of this process. Lastly, in HeLa and HT1080 cells, 4\% of the genome, including tandemly arrayed genes, tRNAs, highly repetitive centromeric, pericentromeric, telomeric, and satellite sequences are embedded in the perinucleolar heterochromatin $[30,31]$. The close proximity between the nucleolus and these so-called nucleolus-associated chromosomal domains further suggests a role for the nucleolus in spatial genome organization. Altogether, these systematic approaches provide a wealth of information that can serve as a strong foundation for future mechanistic studies to elucidate the interplay between the nucleolus, the DDR, chromatin and spatial genome organization in the maintenance of genome stability and cancer prevention.

\section{Conflicts between replication and transcription machineries at the rDNA genes as a source of genomic instability}

Mounting evidence indicates that DNA replication machinery frequently encounters obstacles, which can slow down or stall replication fork progression, leading to DNA damage and recombination. Insults causing such replication stress (RS) include: DNA secondary structures, heterochromatin, DNA lesions, torsional stress in DNA, tightly DNA-bound proteins and transcribed genes [32, 33]. The transcriptional machinery presents a particularly severe impediment to DNA replication, and clashes between these two molecular machineries represent the major source of genomic instability, an event fueling the acquisition of all cancer hallmarks [34-37]. Given that rDNA genes are the most highly transcribed genes in eukaryotes, conflicts between transcription and replication are especially frequent at rDNA gene clusters [38]. To better understand how conflicts between rDNA transcription and replication machineries occur and how they contribute to genome instability, we will first briefly describe what is known about the causes and consequences of these conflicts at the other genomic regions [39].

Head-on convergence between DNA replication forks and transcription machineries may trigger local accumulation of positive DNA supercoils, which likely block replication fork progression, leading to fork slowing and stalling [37, 40]. Such persistent fork stalling can lead to occurrence of long stretches of single-stranded DNA (ssDNA) and single-strand DNA breaks (SSBs), events which trigger a checkpoint surveillance program orchestrated by the ATR-Chk1 kinase signaling module [41-43]. These kinases phosphorylate many factors that function to prevent genome instability by: stabilizing the replication fork, release of RNA polymerase and termination of transcription, activating dormant origins of replication around the stalled forks to facilitate the replication of affected regions, blocking late origin activation, orchestrating DNA repair with restart of stalled forks and cell-cycle inhibition [28, 32, 44]. Under persistent RS or when the ATRdependent RS-response fails, stalled forks may collapse, leading to dissociation of replisome proteins and conversion of SSBs into double-strand breaks (DSBs), the most deleterious of DNA lesions [32]. DSBs trigger activation of the ATM kinase, which orchestrates cell-cycle arrest and DSB repair. If repair is successful, DNA replication resumes [45, 46]. However, when the ATR checkpoint is malfunctional and/or error-prone DNA repair processes are engaged, various genomic alterations may result from RS, including: point mutations, deletions or amplifications, loss of heterozygosity, gross chromosomal rearrangements, and structural and numerical chromosomal aberrations if unreplicated DNA or unresolved repair intermediates persist until mitosis [32, 47].

Recent studies suggest that genomic instability upon clashes of transcriptional and replication machineries depends on transcription-associated R-loop formation [4851]. R-loops form owing to local negative supercoiling behind a transcription bubble, followed by opening of the DNA and formation of highly stable hybrids between nascent RNA and template DNA strands (RNA:DNA hybrid) [48, 49]. The overall load of R-loops increases under perturbed replication and fuels DNA damage and genomic instability (Fig. 2) [34, 52]. Persistent R-loops can also impede RNA Pol elongation, resulting in the pileup of Pol molecules, ultimately provoking replication fork slowing and stalling [50, 53]. The number and length of R-loops increase upon dysregulation of post-transcriptional processes, including packaging of nascent RNAs into ribonucleoprotein particles, mRNA splicing, export or degradation, explaining the association of dysregulation of these post-transcriptional processes and genomic instability [49, 54]. R-loop formation is counteracted by Topoisomerases 1 and 2 (Top1/2), which relieve positive and negative supercoils ahead of and behind transcribing RNA polymerases, respectively, DNA helicases Senataxin that unwinds RNA:DNA hybrids, and RECQ5 that counteracts replication fork stalling in RNA pol I and II transcribed genes, acting at sites of replication-transcription collisions, 


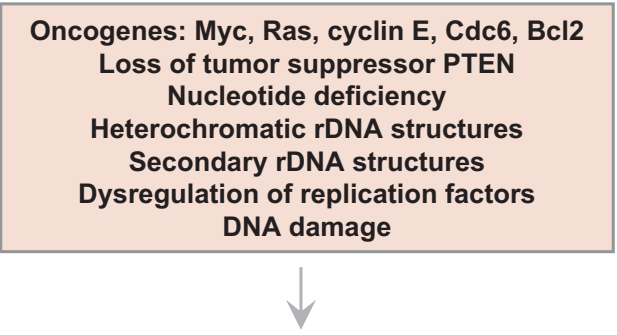

Replication stress
Oncogenes: Myc, Ras, cyclin E, PI3K-Akt-mTORC1

Loss of tumor suppressors: PTEN, Rb, p53, Arf, GSK3 $\beta$

Loss of rDNA silencing

Nutrient signaling pathways

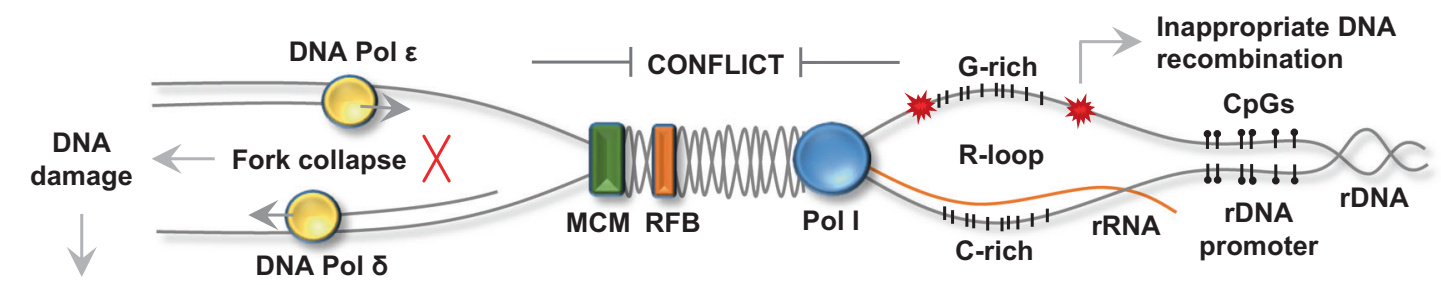

Inappropriate

DNA recombination

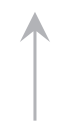

Functional replication checkpoint

Proper rDNA repair

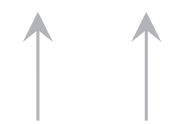

TTF-I Timeless
Top $1 / 2$
Increased Pol I transcription 
loop formation [71], owing to an unmethylated $\mathrm{CpG}$ island in rDNA promoters making the non-template strand G-rich (Fig. 2). A G-rich pre-rRNA outcompetes a G-rich nontemplate rDNA for binding to a C-rich template DNA strand, forming a stable rRNA:rDNA hybrid. Under physiological conditions, R-loop formation at rDNA promoters prevents DNA methylation of $\mathrm{CpG}$ islands by DNA methyltransferase DNMT3B1, thus facilitating rDNA transcription [71]. R-loops are formed co-transcriptionally over the Pol I promoter, the $5^{\prime}$ external transcribed sequence and the $5^{\prime}$ region of the $18 \mathrm{~S}$ rDNA in yeast cells. Loss of Top 1 and RNase $\mathrm{H}$ enhances this inherent formation of R-loops, which then cause severe Pol I pileups and consequent inhibition of pre-rRNA synthesis (Fig. 2) [56]. A subsequent study demonstrated that RS caused by aphidicolin, an inhibitor of replicative DNA polymerases, results in the formation of co-transcriptional R-loops at the $5^{\prime}$ ends of active human rDNA genes, and consequent DNA damage via R-loop-dependent mechanisms (Fig. 2) [71]. This model is further supported by experiments in which depletion of a negative regulator of rDNA transcription, the PHD finger protein 6 (PHF6), led to the formation R-loops and accumulation of R-loop-dependent rDNA damage in human nucleoli [72]. Mutations in the PHF6 gene have been associated with the $\mathrm{X}$-linked mental retardation disorder Borjeson-Forssman-Lehmann syndrome as well as with acute myeloid leukemia, T-cell acute lymphoblastic leukemia and hepatocellular carcinoma, implying that R-loopmediated rDNA damage might contribute to the pathogenesis of these diverse diseases [73, 74]. Whether DSBs in spontaneous human cancers that frequently localize to transcriptionally active rDNA genes are generated through this mechanism remains untested [75]. Mutations in RP genes or ribosome biogenesis assembly factors can cause both inherited and sporadic human cancers [16, 76]. Given that excessive accumulation of nascent mRNAs facilitates the R-loop formation [49, 54], it is plausible that mutations impacting ribosome biogenesis impair pre-rRNA processing, leading to accumulation of unprocessed or partially processed pre-rRNA (Fig. 2). This may facilitate R-loop formation, and thereby interference with DNA replication, rDNA damage, genomic instability, and cancer.

An important question is whether oncogenes and loss of tumor suppressors contribute to cancer pathogenesis by causing rDNA damage. The rate of Pol I transcription is directly or indirectly upregulated by activation of a number of oncogenic pathways, including Myc, PI3K-AktmTORC1, Ras-MAPK, and cyclin E, the loss of tumor suppressors such as PTEN, pRb, p53, ARF, GSK3 $\beta$, or dysregulation of factors that mediate epigenetic events at the rDNA locus (Fig. 2) [77]. It will be critical to assess whether dysregulation of different oncogenic pathways generates damage at specific sites within rDNA genes, given their differential impact on the rate of rDNA transcription, DNA replication process, ROS production and the rate of cell division (Fig. 2) [78-83]. Copies of rDNA that replicate during mid/late $\mathrm{S}$ phase show compact heterochromatic structure suggesting that they are difficult to replicate, particularly under conditions of RS [67]. Consistently, recent work suggests that old hematopoietic stem cells, which characteristically display RS owing to decreased expression of the mini-chromosome maintenance replicative helicase, feature enhanced chromosome breakage in late-replicating, heterochromatic rDNA clusters [84]. Such aberrant replication in rDNA could lead to accumulation of unreplicated or unresolved repair intermediates in mitosis and consequently structural and numerical chromosomal aberrations, as observed elsewhere in the genome [47].

Epigenetic status of the rDNA impacts the susceptibility of rDNA to breakage upon RS caused by folate deficiency, an essential factor for nucleotide biosynthesis. Folate deficiency enhanced DNA damage in the whole-genome [85], but it was particularly prominent in several specific regions of IGSs within rDNA clusters [86]. These breaks sites correspond to histone $\mathrm{H} 3 \mathrm{~K} 4 \mathrm{me} 1$ mark sites and positively correlate with increased recruitment of UBF to rDNA genes and their enhanced transcription [86]. One could speculate that DNA breakage under these conditions is the consequence of clashes between transcriptional and replication machineries [86]. Despite this recent progress, however, mechanisms leading to rDNA damage remain poorly understood.

\section{Repair of rDNA}

Repair of DSBs in rDNA shows some atypical features, reflecting a combination of the more faithful homologous recombination (HR) repair pathway and the more errorprone non-homologous end-joining (NHEJ) pathway [87]. HR repair preserves rDNA stability when the rDNA template is the sister chromatid, yet such rDNA repair can also result in rDNA copy number alterations and genomic rearrangements if it is mediated by unequal sister chromatid recombination or recombination with homologous NORbearing chromosomes [88]. Unequal sister chromatid recombination may reflect malfunctional mechanisms that normally restrict the movement of sister chromatids relative to each other. For example, in yeast strains harboring lowrDNA-copy number most rDNA copies are actively transcribed, and the inability of condensin to bind transcriptionally active rDNA genes interferes with cohesion between sister chromatids at the rDNA loci, resulting in unequal sister chromatid recombination and rDNA instability [89]. In contrast, sufficient numbers of 
Table 1 Inappropriate rDNA repair may lead to chromosomal rearrangements that contribute to cancer

\begin{tabular}{ll}
\hline Chromosomal rearrangements involving rDNA & Consequences \\
\hline rDNA gain & $\begin{array}{l}\text { Increased ribosome biogenesis } \\
\text { Collision between Pol I transcription and replication } \\
\text { machineries }\end{array}$ \\
& $\begin{array}{l}\text { Increased transcription of the remaining rDNA genes } \\
\text { rDNA loss }\end{array}$ \\
& Loss of nucleolar heterochromatin \\
& Centromeric, pericentromeric and telomeric instability \\
& Altered condensin-dependent DNA repair \\
& Genome-wide dysregulation of gene expression \\
& Faster replication of the genome \\
Increased sensitivity to DNA-damaging agents & Unknown \\
\hline Translocations (dicentrinc, multiple jumping) &
\end{tabular}

heterochromatically silent rDNA repeats facilitates condensin association and proper sister chromatid cohesion [89]. It is tempting to speculate that dysregulated balance between active and inactive rDNA genes could also affect the mode of HR at the rDNA genes in human cells via a similar mechanism.

The critical importance of proper regulation of replication and repair at rDNA clusters for tumor suppression was supported by studies of two human cancer-prone syndromes: Ataxia telangiectasia (A-T) and Bloom syndrome, which show 10-fold and 100-fold elevations of the rate of spontaneous alterations in the rDNA gene cluster architecture, respectively $[75,90]$. A-T is caused by mutations in the ATM gene, the kinase product of which orchestrates DSB repair by HR, whereas Bloom syndrome is caused by mutations in the $B L M$ gene encoding a helicase critical for the dissolution of Holliday junctions and abortive HR intermediates, structures that facilitate exchange of chromosome segments between sister chromatids or homologous chromosomes [91, 92]. rDNA gene clusters are also recombinatorial hot spots in human cancers, with over $50 \%$ of lung and colorectal carcinomas showing rDNA rearrangements [75, 93]. Furthermore, genomic rearrangements involving rDNA, including insertions, amplifications, and jumping translocations occur frequently in Hodgkin's lymphoma [94]. These observations indicate that the genomic rearrangements are positively selected for during tumor evolution and that the maintenance of rDNA stability may represent a major tumor-suppressive mechanism.

Notably, besides endogenous rDNA damage, rDNA recombination in human cancer may also reflect exogenously caused DNA damage, a notion consistent with the higher frequency of rDNA alterations in adult solid cancers compared with pediatric cancers [75]. Given that a small proportion of rDNA genes are arranged as inverted (palindromic) repeats, intermolecular recombination between such repeats on the various acrocentric chromosomes might generate dicentric chromosomal translocations linked by an rDNA cluster, somewhat reminiscent of the Robertsonian translocations [7]. It can also be hypothesized that the almost complete nucleotide sequence identity of DJ and PJ sequences surrounding rDNA clusters on acrocentric chromosomes, could predispose these regions as sites of recombination involving these chromosomes [7]. However, direct experimental evidence in support of these hypotheses is still lacking. As discussed above, illegitimate junctions of broken DNA ends during inappropriate DNA repair events may also result in rDNA copy number alterations [88, 95].

\section{The impact of dysregulated rDNA copy number in cancer}

It is plausible that more copies of rDNA genes may confer upon incipient cancer cells a competitive advantage over untransformed cells by providing an increased capacity for ribosome biogenesis and proteosynthesis [96]. Although this may occur in some tumors, recent studies identified lower rDNA copy numbers in several human cancer types compared with adjacent normal tissues [97, 98]. Interestingly, deletion of the mTORC1 negative regulator, tumor suppressor PTEN, in hematopoietic stem cells resulted in a lower rDNA copy number, which preceded their malignant transformation. Notably, these cells showed increased rates of rDNA transcription, proteosynthesis and proliferation, suggesting a compensatory increase in transcriptional activity of the remaining rDNA genes [97]. Furthermore, the finding that specific cancer types harboring lower rDNA copy number show mutational activation of mTORC1, suggests that increased mTORC1 activity might fuel rDNA damage and consequent inappropriate recombination and loss of rDNA copies, likely via mTORC1-dependent 


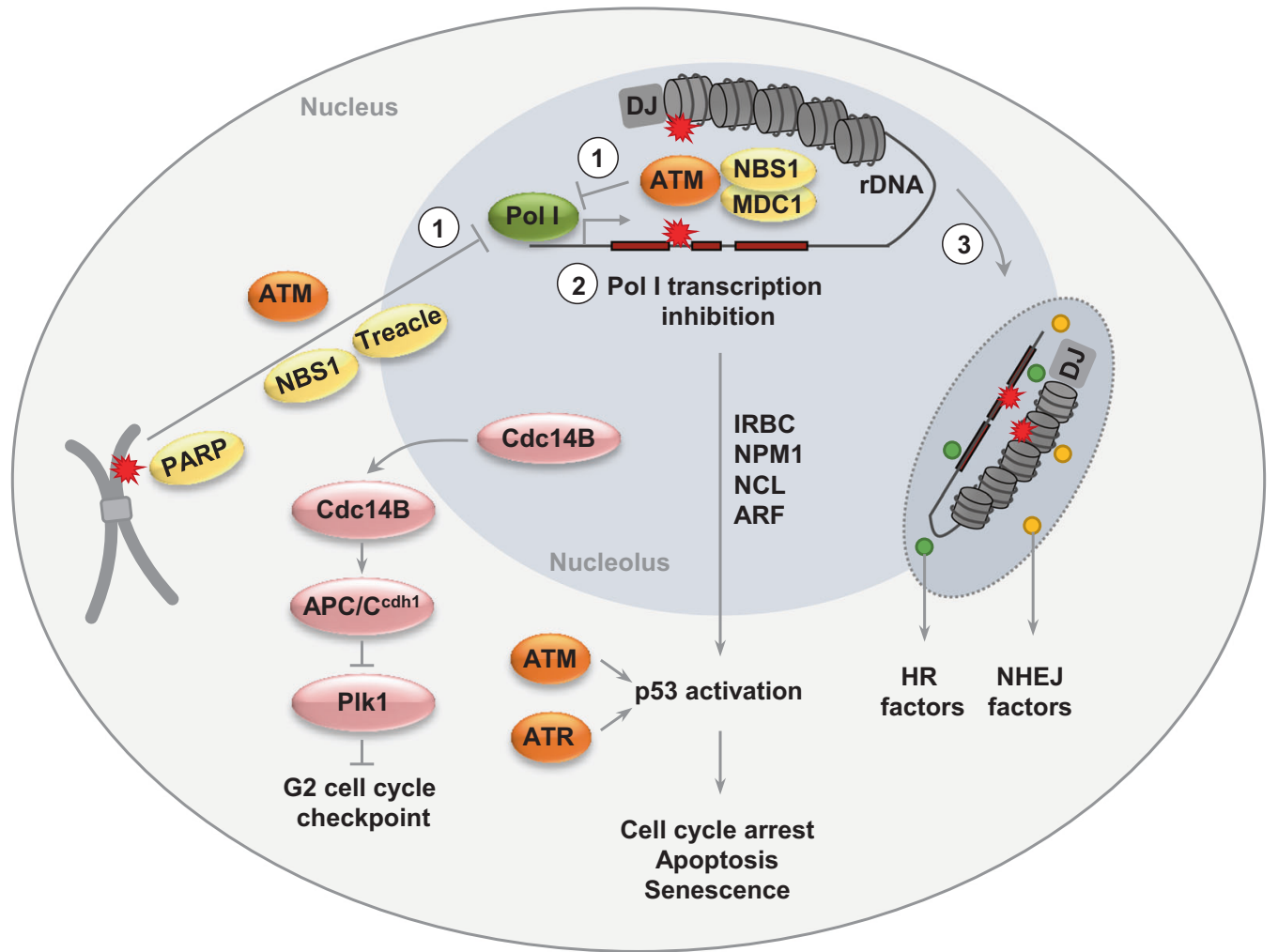

Fig. 3 Nucleolar response to nuclear or nucleolar DNA damage. DSBs in the nuclear chromatin cause Pol I inhibition in the nucleolus through an ATM-dependent signaling pathway, which includes NBS1, PARP, and Treacle. Pol $\mathrm{I}$ is also inhibited upon direct rDNA damage in an ATM-NBS1-MDC1-dependent manner. Inhibition of Pol I transcription is most likely responsible for the formation of nucleolar caps and relocalization of damaged rDNA to this structures, which are enriched in HR and NHEJ factors, thus providing an optimal environment for proper rDNA repair. Notably, cap formation was not observed upon nuclear DNA damage is several studies, in spite of Pol I inhibition. DDR and associated Pol I inhibition activate p53 through the impaired ribosome biogenesis checkpoint (IRBC), NMP1, NCL, ARF, ATM, and ATR. Upon genotoxic stress, Cdc14B is released from the nucleolus to the nucleoplasm where it promotes $\mathrm{APC} / \mathrm{C}^{\mathrm{Cdh} 1}$-dependent Plk1 degradation, triggering a G2-phase cell-cycle checkpoint. Asterisks indicate DSBs upregulation of rDNA transcription [97, 99]. Consistent with such model, hyperactivation of mTOR in Drosophila melanogaster by mutations in components of the insulin/ mTOR signaling axis or excessive nutrient uptake instigated loss of rDNA copies [100]. Mutations in the TP53 gene have also been positively correlated with decreased rDNA copy numbers in several cancer types [98].

These studies provoke the question: how would cancer cells benefit from a decrease in rDNA copy number? A lower rDNA copy number could potentially decrease rDNA heterochromatin levels and alter the balance of nuclear heterochromatin/euchromatin, increase transcription of the remaining rDNA genes, dysregulate gene expression genome-wide and promote illegitimate recombination between highly repetitive DNA sequences (Table 1) [89, 101, 102]. Any or all of these features may explain why the rDNA loss could be positively selected for during cancer evolution [97]. Furthermore, mutations of genes required for heterochromatin formation in Drosophila and human cells led to decreased rDNA copy numbers and promoted global genome instability [11, 103]. These studies underscore the intimate link between rDNA copy number, global heterochromatin, and regulation of genome stability, with important implications for cancer pathogenesis. An additional explanation for how would cancer cells benefit from decreased rDNA copy numbers is that the loss of heterochromatic rDNA genes, which are hard-to-replicate, may allow faster replication of the genome, thereby providing the incipient cancer cells with a growth advantage (Table 1) [67, 97].

Ample evidence implicates dysregulated insulin/ mTORC1 signaling and TP53 mutations in cancer pathogenesis [104-108]. Indeed, decreased rDNA copy number may contribute to tumorigenesis driven via increased insulin/mTOR signaling activity or TP53 aberrations [97, 98]. However, lower rDNA copy numbers may be necessary but not sufficient to drive cancer or they may be just a consequence of malignant transformation. These possibilities are consistent with the observation that many healthy individuals harbor low-rDNA copy number $[97,109]$. 


\section{DDR coordinates Pol I inhibition with rDNA repair}

DDR signaling regulates multiple cellular activities, including inhibition of Pol I transcriptional activity (Fig. 3) [29], and promotion of nucleolar cap formation with recruited DNA repair factors, thereby preventing collisions with DNA repair machineries and providing an optimal environment for rDNA repair $[29,110,111]$. Two modes of DSB-induced Pol I transcriptional inhibition depend on ATM [29]. First, signaling from ionizing radiation (IR)induced DSBs transiently represses rDNA transcription via ATM, Nijmegen breakage syndrome 1 (NBS1) and mediator of DNA-damage checkpoint protein 1 (MDC1) (Fig. 3) [112], accompanied by segregation of the nucleolar protein UBF into nucleolar caps. When DSBs were locally introduced using laser micro-irradiation in individual nucleoli, inhibition of rDNA transcription did not spread to surrounding nucleoli. Inhibition of Pol I was absent in ATMnull murine fibroblasts, NBS1- or MDC1-depleted cells upon IR [112]. Molecularly, the ATM-NBS1-MDC1 signaling interfered with Pol I initiation complex assembly followed by displacement of the elongating Pol I holoenzymes from rDNA [112]. Second, more recent studies described how inhibition of Pol I transcription occurs in response to DSBs introduced in chromatin outside the nucleoli (Fig. 3) [110, 113, 114]. This response featured ATM-dependent accumulation of NBS1 specifically in actively transcribed nucleolar regions of rDNA, temporally correlating with inhibition of rDNA transcription [114]. In this setting, inhibition of rDNA transcription occurred in all nucleoli of a cell even when DSBs were introduced outside of the nucleoli. Mechanistically, NBS1 recruitment into the nucleoli required interaction with the nucleolar protein Treacle (encoded by the TCOF1 gene), but not the usual NBS1 partner, MRE11 (Fig. 3) [114].

Pol I activity can also be inhibited upon DNA damage in DNA-PK- and PARP-1-dependent manner [115]. Finally, the proteins TopBP1 and ATR also co-operate to inhibit pre-rRNA synthesis upon DNA damage and RS [116]. Collectively, available data suggest roles for ATM, ATR, and DNA-PK kinases in downregulation of rDNA transcription following DNA damage.

Where and how are DSBs in rDNA repaired in mammalian cells? Induction of DSBs within the rDNA repeats by either CRISPR-cas9 technology or I-PpoI expression resulted in nucleolar cap formation and downregulation of Pol I transcription in an ATM-dependent manner (Fig. 3) [110, 111]. Damaged rDNA moves from the nucleolar interior to the periphery where it is accessible to DNA repair factors (Fig. 3). NHEJ was the predominant mode of DSB repair [110] but DSBs within rDNA may also recruit the HR machinery throughout the cell cycle (Fig. 3) [95, 111].
DNA synthesis indicative of HR at damaged NORs was observed in G1 suggesting that damaged rDNA that cannot be re-joined by NHEJ factors is recognized and repaired by the HR machinery at the nucleolar periphery (Fig. 3) [111]. Chromosomal context may impact nuclear DSB signaling to nucleoli, as DSBs in the distal junction, a genomic sequence immediately distal to the rDNA arrays, did not inhibit rDNA transcription [111].

There are several putative nucleolar ATM targets of relevance for rDNA silencing, including Pol I subunits RPA34 and TAF1C [29]. PHF6 is another candidate ATM substrate, known to interact with UBF at the rDNA promoter region [29]. The importance of these ATM-dependent mechanisms is apparent in cells from A-T patients, which show a 10-fold increase in spontaneous rDNA alterations over normal cells $[75,90]$. One can also speculate that a failure to mount these protective DDR responses in cancer cells may increase their vulnerability to genotoxic treatments.

\section{Nucleolar stress responses triggered by DNA damage and oncogenic stress}

The nucleolus responds to different types of DNA damage and oncogenic stressors by activating diverse signaling pathways that affect cell-cycle progression in both p53dependent and -independent manners, trigger cellular senescence and promote DNA repair [117]. It is well established that upon impairment of ribosome biogenesis RPL11 (uL5) and RPL5 (uL18), trigger p53 activation [16, 118-124]. RPL11 and RPL5 activate p53 as constituents of the $5 \mathrm{~S}$ ribonucleoprotein particle that also contains $5 \mathrm{~S}$ rRNA [124-126]. This response was recently termed the Impaired Ribosome Biogenesis Checkpoint (IRBC) [127]. Mechanisticly, impairment of any step of ribosome biogenesis leads to redirection of the nascent IRBC from the assembly into pre-60S ribosomes towards inhibition of MDM2, the E3 ligase that negatively regulates p53 [124126]. DDR signaling often converges on the inhibition of rDNA transcription, which may trigger activation of $\mathrm{p} 53$ by the IRBC-dependent mechanism (Fig. 3) [19]. In addition, oncogenic stresses also trigger the IRBC-mediated cellular senescence by enhancing rDNA transcription and delaying rRNA processing, further highlighting the complexity of the nucleolar stress signaling [128]. However, further research should uncover the role(s) of the IRBC-mediated mechanisms in cancer pathogenesis caused by DNA-damaging and oncogenic stressors.

In addition to the IRBC, DNA damage triggeres additional nucleolar signaling pathways, which may or may not co-operate with the IRBC in p53 activation (Fig. 3). For example, the protein interacting with carboxyl terminus 1 
regulates the IRBC via interaction with RPL11 under impaired ribosome biogenesis [129] but also links ATM signaling to the IRBC upon DNA damage [130].

The tumor suppressor protein ARF acts as key activator of the p53 stress signaling pathway by inhibiting MDM2 in response to oncogene activation but is also involved in controlling nucleolar structure and limiting protein synthesis (Fig. 3) [131, 132]. Despite it was originally suggested that the ARF-MDM2 and IRBC-MDM2 pathways are distinct, it appears that the IRBC also sets the level of p53 activation by ARF [125].

The abundant nucleolar protein nucleophosmin (NPM1) interacts constitutively with ARF, sequestering it in the nucleolus [133]. Upon genotoxic stress, modifications of NPM1 lead to the release of ARF which then translocates to the nucleoplasm, where it inhibits MDM2. Notably, NPM1 directly binds MDM2 and p53 to regulate the MDM2-p53 pathway in an ARF-independent manner. For example, UV damage triggers NPM1 translocation from the nucleolus to the nucleoplasm where NPM1-MDM2 complexes are formed [134]. Interestingly, NPM1-ARF interaction may have an important role upon DNA damage in the absence of ATM. Active ATM phosphorylates protein phosphatase 1, which dephosphorylates NPM1 in the nucleolus, thereby weakening the binding between ARF and NPM1 [135]. This allows ARF to translocate to the nucleus where it is degraded by the ubiquitin ligase of ARF (ULF) [135]. In contrast, ATM loss promotes ARF accumulation, which may activate p53 and inhibit ribosome biogenesis, acting as a potential tumor suppressor back-up mechanism following DNA damage in cells with compromised ATM function.

Several other examples of the interplay between NPM1 and DDR mechanisms, particularly DNA repair pathways, have been identified. NPM1 is essential for embryonic development and its loss was associated with DNA damage and genome instability [136, 137]. Interestingly, NPM1 colocalizes with $\gamma \mathrm{H} 2 \mathrm{AX}$ following $\gamma$-irradiation (IR) and contributes to DSB repair [138]. NPM1 phosphorylated at residue Thr199 is recruited to IR-induced DSBs through K63-linked ubiquitination mediated by RNF8/RNF168 [138]. Furthermore, NPM1 is involved in DNA repair of ssDNA lesions by BER and NER repair pathways, reviewed in ref139. Similar to NPM1, another abundant nucleolar protein, nucleolin (NCL), associates with a number of DDR proteins near DSBs [140]. Reduced levels of NCL negatively affect accumulation of specific DDR proteins, DSB repair and weaken ATM-dependent cell-cycle checkpoints [140]. Analogous to NPM1, NCL interacts with MDM2, disrupting its association with p53 [141]. Furthermore, NCL binds both $5^{\prime}$ and $3^{\prime}$-UTR of p53 mRNA to repress its translation, but is outcompeted by ribosomal protein RPL26 following IR to boost p53 mRNA translation [142]. Other molecular interactions between NCL and the DDR machinery have been reviewed elsewhere [143]. Whether NPM1 and NCL are also involved in sensing and repair of potential rDNA damage and/or in sensing defective prerRNA processing remains to be determined.

Furthermore, dual specificity phosphatase cell division cycle 14B is also released from the nucleolus upon genotoxic stress to dephosphorylate and activate the anaphasepromoting complex/cyclosome/(APC/ $\left.\mathrm{C}^{\mathrm{Cdh} 1}\right)$ ubiquitin ligase in the nucleoplasm, leading to polo-like kinase degradation, and the consequent execution of a G2-phase cell-cycle checkpoint [144].

On the other hand, several signaling pathways previously linked to DNA damage are activated in cells upon specific impairments of ribosome biogenesis. The most convincing evidence so far points to activation of the ATR-Chk1dependent G2/M cell-cycle checkpoint pathway in cells treated with low concentrations of actinomycin $\mathrm{D}$, which specifically inhibits Pol I activity [145]. Additional studies showed that both the ATR-Chk1 and ATM-Chk2 signaling pathways are active in RP-deficient cells, for example in RPS19-depleted cells [146]. What could be the trigger for activation of these canonical DDR pathways under such conditions? The accumulation of pre-rRNA upon pre-rRNA processing defects may facilitate the formation of R-loops, leading to DNA RS and rDNA damage as discussed in Section 3 [147]. Moreover, the increased demand for rRNA in RP-deficient cells could lead to compensatory transcriptional activation of silent rDNA genes, with the ensuing DNA topological stress, R-loop formation and rDNA damage [147]. Finally, an imbalance in nucleotide pools owing to defects in pre-rRNA synthesis may also cause DNA RS and activation of the ATR/Chk1-signaling pathway [146].

In view of the extensive interaction between DDR and ribosome biogenesis it comes as no surprise that their functions are dysregulated in many cancer types and that the mechanism of action of many DNA-damaging chemotherapeutics used for cancer treatment involves either the inhibition of pre-rRNA synthesis or its maturation in both DDR-dependent and -independent manners [16, 19, 148]. However, the relative contribution of these ribosome biogenesis impairments to their anticancer efficacy still remains to be determined.

\section{Role of the nucleolus in chromatin and genome organization}

In addition to a decrease in rDNA copy number, disruption of the heterochromatin architecture surrounding nucleoli is seen in cells depleted of specific RPs, indicating that 
alterations of the fine balance between ribosome biogenesis and chromatin organization could be an unanticipated mechanism by which RP-deficiencies mediate pathological phenotypes [76, 149].

Different protein complexes, in part through association with RNA genes transcribed by RNA pol III ( $5 \mathrm{~S}$ rRNA, tRNA), and RNA species (e.g., long non-coding RNA) may be involved in the establishment and maintenance of nucleolus-chromatin domain interactions. One nucleoluschromatin tethering candidate is CCCTC-binding factor (CTCF), a sequence-specific DNA binding protein that acts as a transcriptional repressor, and delimits juxtaposed domains of active and inactive chromatin [150]. CTCF loss in HeLa cells resulted in nucleolar fragmentation and reduced rDNA silencing [151]. Similarly, in Drosophila cells, CTCF loss resulted in nucleolar fragmentation and activation of silent rDNA [152].

Some members of the nucleoplasmin/NPM1 family of histone chaperones [153] including NPM1, NPM2, and dNLP share the nucleolar localization and various nucleolar activities. In a landmark paper, the Drosophila nucleoplasmin-like protein (dNLP), CTCF, and the nucleolar protein Modulo (homolog of mammalian NCL), proved to be essential for the positioning of centromeres near the nucleolus [154]. Centromere clustering during interphase occur in different organisms and cell types, and often around the nucleolus. dNLP and CTCF were sufficient for clustering, whereas Modulo served as the nucleolar anchor. Interestingly, in this case, unclustering of centromeres resulted in spatial destabilization of pericentric heterochromatin, partial defects in the silencing of repetitive elements, defects during chromosome segregation, and subsequent genome instability [154]. Of particular interest is that NPM1 also interacts with CTCF in mammalian cells and may function in a similar fashion [150].

Another example comes from studies on the mammalian maternal oocyte nucleolus, a structure essential for early embryonic development in mammals $[155,156]$. Zygotes derived from enucleolated oocytes exhibit abnormal heterochromatin formation around parental pericentromeric DNA, causing mitotic delay and frequent chromosome missegregation in the first mitotic division [156]. It is well known that the mouse nucleoplasmin-like protein $\mathrm{Npm} 2$ accumulates in oocyte nuclei and nucleoli, and its persistence there in preimplantation embryos is critical for nucleolar formation and embryonic development [157]. Npm2-deficient oocytes lack normal nucleolar structure, not being surrounded by heterochromatin, and display chromosome segregation defects similar to those in enucleolated oocytes [156]. Remarkably, expression of Npm2 alone was sufficient to reconstitute the nucleolar structure in enucleolated embryos and rescued the first mitotic division and full-term development [156].
Interestingly, the nucleolar phenotype in NPM1-depleted cells displays similarities to that observed in Npm2deficient oocytes [158]. Moreover, cells derived from Npm1 knockout mice exhibit extensive genome instability and mitotic defects in analogy with Npm2 [158]. Chronic and acute NPM1 loss disrupts normal nucleolar morphology and triggers rearrangement of perinucleolar heterochromatin indicating a function of NPM1 in the spatial organization of nucleolus-associated heterochromatin similar to NPM2 [159].

All together, these findings further highlight the importance of the nucleolus as a platform for the organization of chromatin and regulation of genomic stability.

\section{Conclusions}

Intense research efforts over the last decade have suggested that the maintenance of rDNA stability is critical for normal structure and functions of the nucleoli but also for genome maintenance, global chromatin regulation, and genomewide gene expression. It is also becoming evident that instability of rDNA gene clusters may be an early event in tumorigenesis and a driving force in human cancer. Quantification of rDNA copy number could be used in the future to gain a more precise insight into the extent of rDNA copy number variations in various cancer types [97]. Similar to yeast, the loss of rDNA copies increases the sensitivity of cancer cells to DNA-damaging agents (Table 1) [89, 97]. Thus, rDNA copy number could be a cancer patient stratification marker to guide genotoxic therapies. The observations that almost $10 \%$ of yeast genes are involved in the maintenance rDNA stability suggests that the mechanisms contributing to rDNA instability described in this review are most likely just the tip of the iceberg [160]. These genes are involved in numerous cellular processes including DNA repair, DNA metabolic processes, epigenetic regulation, transcription, amino-acid transport, protein modifications, ribosome biogenesis, protein synthesis, and regulation of cell cycle. Addressing roles of the human homologs of these genes in genome maintenance and cancer pathogenesis may be another fruitful avenue for future investigations. Given the observation that upregulation of mTOR activity by excessive nutrient uptake in D. melanogaster instigated loss of rDNA copies [100], future studies of this phenomenon are warranted in humans, particularly because the well documented links between overnutrition, obesity, high insulin levels and dyregulation of the mTORC1-signaling pathway with the pathogenesis of cancer [104-107]. Taken together, future studies on the role of the nucleolus in the regulation of genome stability could have huge implications for anticancer therapies as well as cancer prevention measures. 
Acknowledgements We thank Dr. R. Loewith for critical reading of the manuscript. S.V's laboratory is funded by the Croatian Science Foundation (CSF) (grant number: 2079), J.B. laboratory in Stockholm is funded by grants from Karolinska Institutet; the Swedish Cancer Society (grant number: 170176); and the Swedish Research Council (VR-MH 2014-46602-117891-30). M.L. is supported by King Gustaf V's Jubilee Foundation (grant number: 134082).

\section{Compliance with ethical standards}

Conflict of interest The authors declare that they have no competing interests.

Open Access This article is licensed under a Creative Commons Attribution-NonCommercial-NoDerivatives 4.0 International License, which permits any non-commercial use, sharing, distribution and reproduction in any medium or format, as long as you give appropriate credit to the original author(s) and the source, and provide a link to the Creative Commons license. You do not have permission under this license to share adapted material derived from this article or parts of it. The images or other third party material in this article are included in the article's Creative Commons license, unless indicated otherwise in a credit line to the material. If material is not included in the article's Creative Commons license and your intended use is not permitted by statutory regulation or exceeds the permitted use, you will need to obtain permission directly from the copyright holder. To view a copy of this license, visit http://creativecommons.org/licenses/by-nc-nd/4.0/.

\section{References}

1. Pederson T. The nucleolus. Cold Spring Harb Perspect Biol. 2011;3:a000638.

2. Anger AM, Armache JP, Berninghausen O, Habeck M, Subklewe M, Wilson DN, et al. Structures of the human and Drosophila 80S ribosome. Nature. 2013;497:80-85.

3. Budkevich TV, El'skaya AV, Nierhaus KH. Features of $80 \mathrm{~S}$ mammalian ribosome and its subunits. Nucleic Acids Res. 2008;36:4736-4744.

4. McStay B. Nucleolar organizer regions: genomic 'dark matter' requiring illumination. Genes Dev. 2016;30:1598-1610.

5. Stults DM, Killen MW, Pierce HH, Pierce AJ. Genomic architecture and inheritance of human ribosomal RNA gene clusters. Genome Res. 2008;18:13-18.

6. Goodfellow SJ, Zomerdijk JC. Basic mechanisms in RNA polymerase I transcription of the ribosomal RNA genes. Subcell Biochem. 2013;61:211-36.

7. Floutsakou I, Agrawal S, Nguyen TT, Seoighe C, Ganley AR, McStay B. The shared genomic architecture of human nucleolar organizer regions. Genome Res. 2013;23:2003-2012.

8. Grob A, Colleran C, McStay B. Construction of synthetic nucleoli in human cells reveals how a major functional nuclear domain is formed and propagated through cell division. Genes Dev. 2014;28:220-230.

9. Akhmanova A, Verkerk T, Langeveld A, Grosveld F, Galjart N. Characterisation of transcriptionally active and inactive chromatin domains in neurons. J Cell Sci. 2000;113:4463-4474.

10. McStay B, Grummt I. The epigenetics of rRNA genes: from molecular to chromosome biology. Annu Rev Cell Dev Biol. 2008;24:131-157.

11. Guetg C, Lienemann P, Sirri V, Grummt I, Hernandez-Verdun $\mathrm{D}$, Hottiger MO, et al. The NoRC complex mediates the heterochromatin formation and stability of silent rRNA genes and centromeric repeats. EMBO J. 2010;29:2135-2146.
12. Rudra D, Warner JR. What better measure than ribosome synthesis? Genes Dev. 2004;18:2431-2436.

13. Lane AN, Fan TW. Regulation of mammalian nucleotide metabolism and biosynthesis. Nucleic Acids Res. 2015;43:2466-2485.

14. Murayama A, Ohmori K, Fujimura A, Minami H, YasuzawaTanaka K, Kuroda T, et al. Epigenetic control of rDNA loci in response to intracellular energy status. Cell. 2008;133:627-39.

15. Xie W, Ling T, Zhou Y, Feng W, Zhu Q, Stunnenberg HG, et al. The chromatin remodeling complex NuRD establishes the poised state of rRNA genes characterized by bivalent histone modifications and altered nucleosome positions. Proc Natl Acad Sci USA. 2012;109:8161-8166.

16. Bursac S, Brdovcak MC, Donati G, Volarevic S. Activation of the tumor suppressor p53 upon impairment of ribosome biogenesis. Biochim Biophys Acta. 2014;1842:817-830.

17. Xue S, Barna M. Specialized ribosomes: a new frontier in gene regulation and organismal biology. Nat Rev Mol Cell Biol. 2012;13:355-369.

18. Tschochner H, Hurt E. Pre-ribosomes on the road from the nucleolus to the cytoplasm. Trends Cell Biol. 2003;13:255-263.

19. Orsolic I, Jurada D, Pullen N, Oren M, Eliopoulos AG, Volarevic S. The relationship between the nucleolus and cancer: current evidence and emerging paradigms. Semin Cancer Biol. 2016;37-38:36-50.

20. Ahmad Y, Boisvert FM, Gregor P, Cobley A, Lamond AI. NOPdb: nucleolar proteome database--2008 update. Nucleic Acids Res. 2009;37:D181-D184.

21. Diesch J, Hannan RD, Sanij E. Perturbations at the ribosomal genes loci are at the centre of cellular dysfunction and human disease. Cell Biosci. 2014;4:43.

22. Durkin SG, Glover TW. Chromosome fragile sites. Annu Rev Genet. 2007;41:169-192.

23. Ogawa LM, Baserga SJ. Crosstalk between the nucleolus and the DNA damage response. Mol Biosyst. 2017;13:443-455.

24. Hutten S, Prescott A, James J, Riesenberg S, Boulon S, Lam YW, et al. An intranucleolar body associated with rDNA. Chromosoma. 2011;120:481-499.

25. Wild T, Horvath P, Wyler E, Widmann B, Badertscher L, Zemp $\mathrm{I}$, et al. A protein inventory of human ribosome biogenesis reveals an essential function of exportin 5 in $60 \mathrm{~S}$ subunit export. PLoS Biol. 2010;8:e1000522.

26. Tafforeau L, Zorbas C, Langhendries JL, Mullineux ST, Stamatopoulou V, Mullier R, et al. The complexity of human ribosome biogenesis revealed by systematic nucleolar screening of Pre-rRNA processing factors. Mol Cell. 2013;51:539-551.

27. Badertscher L, Wild T, Montellese C, Alexander LT, Bammert L, Sarazova M, et al. Genome-wide RNAi screening identifies protein modules required for $40 \mathrm{~S}$ subunit synthesis in human cells. Cell Rep. 2015;13:2879-2891.

28. Matsuoka S, Ballif BA, Smogorzewska A, McDonald ER 3rd, Hurov KE, Luo J, et al. ATM and ATR substrate analysis reveals extensive protein networks responsive to DNA damage. Science. 2007;316:1160-1166.

29. Larsen DH, Stucki M. Nucleolar responses to DNA doublestrand breaks. Nucleic Acids Res. 2016;44:538-544.

30. Nemeth A, Conesa A, Santoyo-Lopez J, Medina I, Montaner D, Peterfia B, et al. Initial genomics of the human nucleolus. PLoS Genet. 2010;6:e1000889.

31. van Koningsbruggen S, Gierlinski M, Schofield P, Martin D, Barton GJ, Ariyurek Y, et al. High-resolution whole-genome sequencing reveals that specific chromatin domains from most human chromosomes associate with nucleoli. Mol Biol Cell. 2010;21:3735-3748.

32. Gaillard H, Garcia-Muse T, Aguilera A. Replication stress and cancer. Nat Rev Cancer. 2015;15:276-289. 
33. Gottipati P, Cassel TN, Savolainen L, Helleday T. Transcriptionassociated recombination is dependent on replication in mammalian cells. Mol Cell Biol. 2008;28:154-164.

34. Helmrich A, Ballarino M, Tora L. Collisions between replication and transcription complexes cause common fragile site instability at the longest human genes. Mol Cell. 2011;44:966-977.

35. Helmrich A, Ballarino M, Nudler E, Tora L. Transcriptionreplication encounters, consequences and genomic instability. Nat Struct Mol Biol. 2013;20:412-418.

36. Kim N, Jinks-Robertson S. Transcription as a source of genome instability. Nat Rev Genet. 2012;13:204-214.

37. Prado F, Aguilera A. Impairment of replication fork progression mediates RNA polII transcription-associated recombination. EMBO J. 2005;24:1267-1276.

38. Takeuchi Y, Horiuchi T, Kobayashi T. Transcription-dependent recombination and the role of fork collision in yeast rDNA. Genes Dev. 2003;17:1497-1506.

39. Garcia-Muse T, Aguilera A. Transcription-replication conflicts: how they occur and how they are resolved. Nat Rev Mol Cell Biol. 2016;17:553-563.

40. Azvolinsky A, Giresi PG, Lieb JD, Zakian VA. Highly transcribed RNA polymerase II genes are impediments to replication fork progression in Saccharomyces cerevisiae. Mol Cell. 2009;34:722-734.

41. Shechter D, Costanzo V, Gautier J. ATR and ATM regulate the timing of DNA replication origin firing. Nat Cell Biol. 2004;6:648-655.

42. Zou L, Elledge SJ. Sensing DNA damage through ATRIP recognition of RPA-ssDNA complexes. Science. 2003;300:1542-1548.

43. Jazayeri A, Falck J, Lukas C, Bartek J, Smith GC, Lukas J, et al. ATM- and cell cycle-dependent regulation of ATR in response to DNA double-strand breaks. Nat Cell Biol. 2006;8:37-45.

44. Toledo LI, Altmeyer M, Rask MB, Lukas C, Larsen DH, Povlsen LK, et al. ATR prohibits replication catastrophe by preventing global exhaustion of RPA. Cell. 2013;155:1088-1103.

45. Shiloh Y. ATM and related protein kinases: safeguarding genome integrity. Nat Rev Cancer. 2003;3:155-168.

46. Moynahan ME, Jasin M. Mitotic homologous recombination maintains genomic stability and suppresses tumorigenesis. Nat Rev Mol Cell Biol. 2010;11:196-207.

47. Burrell RA, McClelland SE, Endesfelder D, Groth P, Weller MC, Shaikh N, et al. Replication stress links structural and numerical cancer chromosomal instability. Nature. 2013;494:492-496.

48. Aguilera A, Gomez-Gonzalez B. Genome instability: a mechanistic view of its causes and consequences. Nat Rev Genet. 2008;9:204-217.

49. Li X, Manley JL. Cotranscriptional processes and their influence on genome stability. Genes Dev. 2006;20:1838-1847.

50. Aguilera A, Garcia-Muse T. R loops: from transcription byproducts to threats to genome stability. Mol Cell. 2012;46:115-124.

51. Hamperl S, Cimprich KA. The contribution of co-transcriptional RNA:DNA hybrid structures to DNA damage and genome instability. DNA Repair (Amst). 2014;19:84-94.

52. Gan W, Guan Z, Liu J, Gui T, Shen K, Manley JL, et al. R-loopmediated genomic instability is caused by impairment of replication fork progression. Genes Dev. 2011;25:2041-2056.

53. Huertas P, Aguilera A. Cotranscriptionally formed DNA:RNA hybrids mediate transcription elongation impairment and transcription-associated recombination. Mol Cell. 2003;12:711-721.

54. Paulsen RD, Soni DV, Wollman R, Hahn AT, Yee MC, Guan A, et al. A genome-wide siRNA screen reveals diverse cellular processes and pathways that mediate genome stability. Mol Cell. 2009;35:228-239.
55. Drolet M, Phoenix P, Menzel R, Masse E, Liu LF, Crouch RJ. Overexpression of RNase $\mathrm{H}$ partially complements the growth defect of an Escherichia coli delta topA mutant: R-loop formation is a major problem in the absence of DNA topoisomerase I. Proc Natl Acad Sci USA. 1995;92:3526-3530.

56. El Hage A, French SL, Beyer AL, Tollervey D. Loss of topoisomerase I leads to R-loop-mediated transcriptional blocks during ribosomal RNA synthesis. Genes Dev. 2010;24:1546-1558.

57. Tuduri S, Crabbe L, Conti C, Tourriere H, Holtgreve-Grez H, Jauch A, et al. Topoisomerase I suppresses genomic instability by preventing interference between replication and transcription. Nat Cell Biol. 2009;11:1315-1324.

58. Yuce O, West SC. Senataxin, defective in the neurodegenerative disorder ataxia with oculomotor apraxia 2, lies at the interface of transcription and the DNA damage response. Mol Cell Biol. 2013;33:406-417.

59. Urban V, Dobrovolna J, Huhn D, Fryzelkova J, Bartek J, Janscak P. RECQ5 helicase promotes resolution of conflicts between replication and transcription in human cells. J Cell Biol. 2016;214:401-415.

60. Hatchi E, Skourti-Stathaki K, Ventz S, Pinello L, Yen A, Kamieniarz-Gdula K, et al. BRCA1 recruitment to transcriptional pause sites is required for R-loop-driven DNA damage repair. Mol Cell. 2015;57:636-647.

61. Schwab RA, Nieminuszczy J, Shah F, Langton J, Lopez Martinez D, Liang CC, et al. The fanconi anemia pathway maintains genome stability by coordinating replication and transcription. Mol Cell. 2015;60:351-361.

62. Sollier J, Stork CT, Garcia-Rubio ML, Paulsen RD, Aguilera A, Cimprich KA. Transcription-coupled nucleotide excision repair factors promote R-loop-induced genome instability. Mol Cell. 2014;56:777-785.

63. Wimberly H, Shee C, Thornton PC, Sivaramakrishnan P, Rosenberg SM, Hastings PJ. R-loops and nicks initiate DNA breakage and genome instability in non-growing Escherichia coli. Nat Commun. 2013;4:2115.

64. Daniel JA, Nussenzweig A. The AID-induced DNA damage response in chromatin. Mol Cell. 2013;50:309-321.

65. French SL, Osheim YN, Cioci F, Nomura M, Beyer AL. In exponentially growing Saccharomyces cerevisiae cells, rRNA synthesis is determined by the summed RNA polymerase I loading rate rather than by the number of active genes. Mol Cell Biol. 2003;23:1558-1568.

66. Berger C, Horlebein A, Gogel E, Grummt F. Temporal order of replication of mouse ribosomal RNA genes during the cell cycle. Chromosoma. 1997;106:479-484.

67. Coffman FD, He M, Diaz ML, Cohen S. DNA replication initiates at different sites in early and late $\mathrm{S}$ phase within human ribosomal RNA genes. Cell Cycle. 2005;4:1223-1226.

68. Dimitrova DS. DNA replication initiation patterns and spatial dynamics of the human ribosomal RNA gene loci. J Cell Sci. 2011;124:2743-2752.

69. Smirnov E, Borkovec J, Kovacik L, Svidenska S, Schrofel A, Skalnikova M, et al. Separation of replication and transcription domains in nucleoli. J Struct Biol. 2014;188:259-266.

70. Akamatsu Y, Kobayashi T. The human RNA polymerase I transcription terminator complex acts as a replication fork barrier that coordinates the progress of replication with rRNA transcription activity. Mol Cell Biol. 2015;35:1871-1881.

71. Ginno PA, Lott PL, Christensen HC, Korf I, Chedin F. R-loop formation is a distinctive characteristic of unmethylated human CpG island promoters. Mol Cell. 2012;45:814-825.

72. Wang J, Leung JW, Gong Z, Feng L, Shi X, Chen J. PHF6 regulates cell cycle progression by suppressing ribosomal RNA synthesis. J Biol Chem. 2013;288:3174-3183. 
73. Visootsak J, Rosner B, Dykens E, Schwartz C, Hahn K, White $\mathrm{SM}$, et al. Clinical and behavioral features of patients with Borjeson-Forssman-Lehmann syndrome with mutations in PHF6. J Pediatr. 2004;145:819-825.

74. Yoo NJ, Kim YR, Lee SH. Somatic mutation of PHF6 gene in Tcell acute lymphoblatic leukemia, acute myelogenous leukemia and hepatocellular carcinoma. Acta Oncol. 2012;51:107-111.

75. Stults DM, Killen MW, Williamson EP, Hourigan JS, Vargas HD, Arnold SM, et al. Human rRNA gene clusters are recombinational hotspots in cancer. Cancer Res. 2009;69:9096-9.

76. Narla A, Ebert BL. Ribosomopathies: human disorders of ribosome dysfunction. Blood. 2010;115:3196-3205.

77. Grummt I. Wisely chosen paths--regulation of rRNA synthesis: delivered on 30 June 2010 at the 35th FEBS Congress in Gothenburg, Sweden. FEBS J. 2010;277:4626-4639.

78. Bartkova J, Horejsi Z, Koed K, Kramer A, Tort F, Zieger K, et al. DNA damage response as a candidate anti-cancer barrier in early human tumorigenesis. Nature. 2005;434:864-870.

79. Halazonetis TD, Gorgoulis VG, Bartek J. An oncogene-induced DNA damage model for cancer development. Science. 2008;319:1352-1355.

80. Ekholm-Reed S, Mendez J, Tedesco D, Zetterberg A, Stillman B, Reed SI. Deregulation of cyclin E in human cells interferes with prereplication complex assembly. J Cell Biol. 2004;165:789-800.

81. Dominguez-Sola D, Gautier J. MYC and the control of DNA replication. Cold Spring Harb Perspect Med 2014; 4:a014423.

82. Feng J, Liang J, Li J, Li Y, Liang H, Zhao X, et al. PTEN controls the DNA replication process through MCM2 in response to replicative stress. Cell Rep. 2015;13:1295-1303.

83. Ogrunc M, Di Micco R, Liontos M, Bombardelli L, Mione M, Fumagalli $\mathrm{M}$, et al. Oncogene-induced reactive oxygen species fuel hyperproliferation and DNA damage response activation. Cell Death Differ. 2014;21:998-1012.

84. Flach J, Bakker ST, Mohrin M, Conroy PC, Pietras EM, Reynaud $\mathrm{D}$, et al. Replication stress is a potent driver of functional decline in ageing haematopoietic stem cells. Nature. 2014;512:198-202.

85. Lamm N, Maoz K, Bester AC, Im MM, Shewach DS, Karni R, et al. Folate levels modulate oncogene-induced replication stress and tumorigenicity. EMBO Mol Med. 2015;7:1138-1152.

86. Xie Q, Li C, Song X, Wu L, Jiang Q, Qiu Z, et al. Folate deficiency facilitates recruitment of upstream binding factor to hot spots of DNA double-strand breaks of rRNA genes and promotes its transcription. Nucleic Acids Res. 2017;45:2472-2489.

87. Chapman JR, Taylor MR, Boulton SJ. Playing the end game: DNA double-strand break repair pathway choice. Mol Cell. 2012;47:497-510.

88. Kobayashi T. Strategies to maintain the stability of the ribosomal RNA gene repeats--collaboration of recombination, cohesion, and condensation. Genes Genet Syst. 2006;81:155-161.

89. Ide S, Miyazaki T, Maki H, Kobayashi T. Abundance of ribosomal RNA gene copies maintains genome integrity. Science. 2010;327:693-696.

90. Killen MW, Stults DM, Adachi N, Hanakahi L, Pierce AJ. Loss of Bloom syndrome protein destabilizes human gene cluster architecture. Hum Mol Genet. 2009;18:3417-3428.

91. Shiloh Y, Ziv Y. The ATM protein kinase: regulating the cellular response to genotoxic stress, and more. Nat Rev Mol Cell Biol. 2013;14:197-210.

92. Wechsler T, Newman S, West SC. Aberrant chromosome morphology in human cells defective for Holliday junction resolution. Nature. 2011;471:642-646.

93. Tchurikov NA, Fedoseeva DM, Sosin DV, Snezhkina AV, Melnikova NV, Kudryavtseva AV, et al. Hot spots of DNA double-strand breaks and genomic contacts of human rDNA units are involved in epigenetic regulation. J Mol Cell Biol. 2015;7:366-382.

94. MacLeod RA, Spitzer D, Bar-Am I, Sylvester JE, Kaufmann M, Wernich A, et al. Karyotypic dissection of Hodgkin's disease cell lines reveals ectopic subtelomeres and ribosomal DNA at sites of multiple jumping translocations and genomic amplification. Leukemia. 2000;14:1803-1814.

95. Warmerdam DO, van den Berg J, Medema RH. Breaks in the 45S rDNA Lead to Recombination-Mediated Loss of Repeats. Cell Rep. 2016;14:2519-2527.

96. Montanaro L, Trere D, Derenzini M. Nucleolus, ribosomes, and cancer. Am J Pathol. 2008;173:301-310.

97. Xu B, Li H, Perry JM, Singh VP, Unruh J, Yu Z, et al. Ribosomal DNA copy number loss and sequence variation in cancer. PLoS Genet. 2017;13:e1006771.

98. Wang M, Lemos B. Ribosomal DNA copy number amplification and loss in human cancers is linked to tumor genetic context, nucleolus activity, and proliferation. PLoS Genet. 2017;13: e1006994.

99. Hannan KM, Brandenburger Y, Jenkins A, Sharkey K, Cavanaugh A, Rothblum L, et al. mTOR-dependent regulation of ribosomal gene transcription requires $\mathrm{S} 6 \mathrm{~K} 1$ and is mediated by phosphorylation of the carboxy-terminal activation domain of the nucleolar transcription factor UBF. Mol Cell Biol. 2003;23:8862-8877.

100. Aldrich JC, Maggert KA. Transgenerational inheritance of dietinduced genome rearrangements in Drosophila. PLoS Genet. 2015;11:e1005148.

101. Paredes S, Maggert KA. Ribosomal DNA contributes to global chromatin regulation. Proc Natl Acad Sci USA. 2009;106:17829-17834.

102. Paredes S, Branco AT, Hartl DL, Maggert KA, Lemos B, Ribosomal DNA. deletions modulate genome-wide gene expression: "rDNA-sensitive" genes and natural variation. PLoS Genet. 2011;7:e1001376.

103. Peng JC, Karpen GH. H3K9 methylation and RNA interference regulate nucleolar organization and repeated DNA stability. Nat Cell Biol. 2007;9:25-35.

104. Giovannucci E, Michaud D. The role of obesity and related metabolic disturbances in cancers of the colon, prostate, and pancreas. Gastroenterology. 2007;132:2208-2225.

105. Hemkens LG, Grouven U, Bender R, Gunster C, Gutschmidt S, Selke GW, et al. Risk of malignancies in patients with diabetes treated with human insulin or insulin analogues: a cohort study. Diabetologia. 2009;52:1732-1744.

106. Yuan TL, Cantley LC. PI3K pathway alterations in cancer: variations on a theme. Oncogene. 2008;27:5497-5510.

107. Sabatini DM. mTOR and cancer: insights into a complex relationship. Nat Rev Cancer. 2006;6:729-734.

108. Muller PA, Vousden KH. Mutant p53 in cancer: new functions and therapeutic opportunities. Cancer Cell. 2014;25:304-317.

109. Gibbons JG, Branco AT, Yu S, Lemos B. Ribosomal DNA copy number is coupled with gene expression variation and mitochondrial abundance in humans. Nat Commun. 2014;5:4850.

110. Harding SM, Boiarsky JA, Greenberg RA. ATM dependent silencing links nucleolar chromatin reorganization to DNA damage recognition. Cell Rep. 2015;13:251-259.

111. van Sluis M, McStay B. A localized nucleolar DNA damage response facilitates recruitment of the homology-directed repair machinery independent of cell cycle stage. Genes Dev. 2015;29:1151-1163.

112. Kruhlak M, Crouch EE, Orlov M, Montano C, Gorski SA, Nussenzweig A, et al. The ATM repair pathway inhibits RNA polymerase I transcription in response to chromosome breaks. Nature. 2007;447:730-734. 
113. Ciccia A, Huang JW, Izhar L, Sowa ME, Harper JW, Elledge SJ. Treacher Collins syndrome TCOF1 protein cooperates with NBS1 in the DNA damage response. Proc Natl Acad Sci USA. 2014;111:18631-18636.

114. Larsen DH, Hari F, Clapperton JA, Gwerder M, Gutsche K, Altmeyer M, et al. The NBS1-Treacle complex controls ribosomal RNA transcription in response to DNA damage. Nat Cell Biol. 2014;16:792-803.

115. Calkins AS, Iglehart JD, Lazaro JB. DNA damage-induced inhibition of rRNA synthesis by DNA-PK and PARP-1. Nucleic Acids Res. 2013;41:7378-7386.

116. Sokka M, Rilla K, Miinalainen I, Pospiech H, Syväoja JE. High levels of TopBP1 induce ATR-dependent shut-down of rRNA transcription and nucleolar segregation. Nucleic Acids Res. 2015;43:4975-4989.

117. Boulon S, Westman BJ, Hutten S, Boisvert FM, Lamond AI. The nucleolus under stress. Mol Cell. 2010;40:216-227.

118. Pestov DG, Strezoska Z, Lau LF. Evidence of p53-dependent cross-talk between ribosome biogenesis and the cell cycle: effects of nucleolar protein Bop1 on G(1)/S transition. Mol Cell Biol. 2001;21:4246-4255.

119. Lohrum MA, Ludwig RL, Kubbutat MH, Hanlon M, Vousden $\mathrm{KH}$. Regulation of HDM2 activity by the ribosomal protein L11. Cancer Cell. 2003;3:577-587.

120. Zhang Y, Wolf GW, Bhat K, Jin A, Allio T, Burkhart WA, et al. Ribosomal protein L11 negatively regulates oncoprotein MDM2 and mediates a p53-dependent ribosomal-stress checkpoint pathway. Mol Cell Biol. 2003;23:8902-8912.

121. Bhat KP, Itahana K, Jin A, Zhang Y. Essential role of ribosomal protein L11 in mediating growth inhibition-induced p53 activation. EMBO J. 2004;23:2402-2412.

122. Dai MS, Lu H. Inhibition of MDM2-mediated p53 ubiquitination and degradation by ribosomal protein L5. J Biol Chem. 2004;279:44475-44482.

123. Fumagalli S, Ivanenkov VV, Teng T, Thomas G. Suprainduction of $\mathrm{p} 53$ by disruption of $40 \mathrm{~S}$ and $60 \mathrm{~S}$ ribosome biogenesis leads to the activation of a novel G2/M checkpoint. Genes Dev. 2012;26:1028-1040.

124. Bursac S, Brdovcak MC, Pfannkuchen M, Orsolic I, Golomb L, Zhu Y, et al. Mutual protection of ribosomal proteins L5 and L11 from degradation is essential for p53 activation upon ribosomal biogenesis stress. Proc Natl Acad Sci USA. 2012;109:20467-20472.

125. Sloan KE, Bohnsack MT, Watkins NJ. The 5S RNP couples p53 homeostasis to ribosome biogenesis and nucleolar stress. Cell Rep. 2013;5:237-247.

126. Donati G, Peddigari S, Mercer CA, Thomas G. $5 \mathrm{~S}$ ribosomal RNA is an essential component of a nascent ribosomal precursor complex that regulates the Hdm2-p53 checkpoint. Cell Rep. 2013;4:87-98.

127. Gentilella A, Moron-Duran FD, Fuentes P, Zweig-Rocha G, Riano-Canalias F, Pelletier J et al. Autogenous control of 5'TOP mRNA stability by 40S ribosomes. Mol Cell. 2017;67:55-70.

128. Nishimura K, Kumazawa T, Kuroda T, Katagiri N, Tsuchiya M, Goto $\mathrm{N}$, et al. Perturbation of ribosome biogenesis drives cells into senescence through 5S RNP-mediated p53 activation. Cell Rep. 2015;10:1310-1323.

129. Sasaki M, Kawahara K, Nishio M, Mimori K, Kogo R, Hamada $\mathrm{K}$, et al. Regulation of the MDM2-P53 pathway and tumor growth by PICT1 via nucleolar RPL11. Nat Med. 2011;17:944-951.

130. Chen H, Han L, Tsai H, Wang Z, Wu Y, Duo Y, et al. PICT-1 is a key nucleolar sensor in DNA damage response signaling that regulates apoptosis through the RPL11-MDM2-p53 pathway. Oncotarget. 2016;7:83241-83257.
131. Apicelli AJ, Maggi LB, Hirbe AC, Miceli AP, Olanich ME, Schulte-Winkeler CL, et al. A non-tumor suppressor role for basal p19ARF in maintaining nucleolar structure and function. Mol Cell Biol. 2008;28:1068-1080.

132. Lessard F, Morin F, Ivanchuk S, Langlois F, Stefanovsky V, Rutka J, et al. The ARF tumor suppressor controls ribosome biogenesis by regulating the RNA polymerase I transcription factor TTF-I. Mol Cell. 2010;38:539-550.

133. Korgaonkar C, Hagen J, Tompkins V, Frazier AA, Allamargot C, Quelle FW, et al. Nucleophosmin (B23) targets ARF to nucleoli and inhibits its function. Mol Cell Biol. 2005;25:1258-1271.

134. Kurki S, Peltonen K, Latonen L, Kiviharju TM, Ojala PM, Meek D, et al. Nucleolar protein NPM interacts with HDM2 and protects tumor suppressor protein p53 from HDM2-mediated degradation. Cancer Cell. 2004;5:465-475.

135. Velimezi G, Liontos M, Vougas K, Roumeliotis T, Bartkova J, Sideridou M, et al. Functional interplay between the DNAdamage-response kinase ATM and ARF tumour suppressor protein in human cancer. Nat Cell Biol. 2013;15:967-977.

136. Colombo E, Bonetti P, Lazzerini Denchi E, Martinelli P, Zamponi R, Marine JC, et al. Nucleophosmin is required for DNA integrity and p19Arf protein stability. Mol Cell Biol. 2005;25:8874-8886.

137. Grisendi S, Bernardi R, Rossi M, Cheng K, Khandker L, Manova K, et al. Role of nucleophosmin in embryonic development and tumorigenesis. Nature. 2005;437:147-153.

138. Koike A, Nishikawa H, Wu W, Okada Y, Venkitaraman AR, Ohta T. Recruitment of phosphorylated NPM1 to sites of DNA damage through RNF8-dependent ubiquitin conjugates. Cancer Res. 2010;70:6746-6756.

139. Antoniali G, Lirussi L, Poletto M, Tell G. Emerging roles of the nucleolus in regulating the DNA damage response: the noncanonical DNA repair enzyme APE1/Ref-1 as a paradigmatical example. Antioxid Redox Signal. 2014;20:621-639.

140. Kobayashi J, Fujimoto H, Sato J, Hayashi I, Burma S, Matsuura $\mathrm{S}$, et al. Nucleolin participates in DNA double-strand breakinduced damage response through MDC1-dependent pathway. PLoS ONE. 2012;7:e49245.

141. Saxena A, Rorie CJ, Dimitrova D, Daniely Y, Borowiec JA. Nucleolin inhibits $\mathrm{Hdm} 2$ by multiple pathways leading to p53 stabilization. Oncogene. 2006;25:7274-2788.

142. Takagi M, Absalon MJ, McLure KG, Kastan MB. Regulation of p53 translation and induction after DNA damage by ribosomal protein L26 and nucleolin. Cell. 2005;123:49-63.

143. Scott DD, Oeffinger M. Nucleolin and nucleophosmin: nucleolar proteins with multiple functions in DNA repair. Biochem Cell Biol. 2016;94:419-32.

144. Bassermann F, Frescas D, Guardavaccaro D, Busino L, Peschiaroli A, Pagano M. The Cdc14B-Cdh1-Plk1 axis controls the G2 DNA-damage-response checkpoint. Cell. 2008;134:256-67.

145. Ma H, Pederson T. The nucleolus stress response is coupled to an ATR-Chk1-mediated G2 arrest. Mol Biol Cell. 2013;24:1334-42.

146. Danilova N, Bibikova E, Covey TM, Nathanson D, Dimitrova E, Konto Y, et al. The role of the DNA damage response in zebrafish and cellular models of Diamond Blackfan anemia. Dis Model Mech. 2014;7:895-905.

147. Bermejo R, Lai MS, Foiani M. Preventing replication stress to maintain genome stability: resolving conflicts between replication and transcription. Mol Cell. 2012;45:710-718.

148. Burger K, Muhl B, Harasim T, Rohrmoser M, Malamoussi A, Orban M, et al. Chemotherapeutic drugs inhibit ribosome biogenesis at various levels. J Biol Chem. 2010;285:12416-12425. 
149. O'Donohue MF, Choesmel V, Faubladier M, Fichant G, Gleizes PE. Functional dichotomy of ribosomal proteins during the synthesis of mammalian 40S ribosomal subunits. J Cell Biol. 2010;190:853-866.

150. Yusufzai TM, Tagami H, Nakatani Y, Felsenfeld G. CTCF tethers an insulator to subnuclear sites, suggesting shared insulator mechanisms across species. Mol Cell. 2004;13:291-298.

151. Hernández-Hernández A, Soto-Reyes E, Ortiz R, Arriaga-Canon C, Echeverría-Martinez OM, Vázquez-Nin GH, et al. Changes of the nucleolus architecture in absence of the nuclear factor CTCF. Cytogenet Genome Res. 2012;136:89-96.

152. Guerrero PA, Maggert KA. The CCCTC-binding factor (CTCF) of Drosophila contributes to the regulation of the ribosomal DNA and nucleolar stability. PloS ONE. 2011;6:e16401.

153. Frehlick LJ, Eirín-López JM, Ausió J. New insights into the nucleophosmin/nucleoplasmin family of nuclear chaperones. Bioessays. 2007;29:49-59.

154. Padeken J, Mendiburo MJ, Chlamydas S, Schwarz H-J, Kremmer E, Heun P. The nucleoplasmin homolog NLP mediates centromere clustering and anchoring to the nucleolus. Mol Cell. 2013;50:236-249.
155. Ogushi S, Palmieri C, Fulka H, Saitou M, Miyano T, Fulka J. The maternal nucleolus is essential for early embryonic development in mammals. Science. 2008;319:613-616.

156. Ogushi S, Yamagata K, Obuse C, Furuta K, Wakayama T, Matzuk MM, et al. Reconstitution of the oocyte nucleolus in mice through a single nucleolar protein, NPM2. J Cell Sci. 2017;130:2416-2429.

157. Burns KH, Viveiros MM, Ren Y, Wang P, DeMayo FJ, Frail $\mathrm{DE}$, et al. Roles of NPM2 in chromatin and nucleolar organization in oocytes and embryos. Science. 2003;300:633-636.

158. Colombo E, Alcalay M, Pelicci PG. Nucleophosmin and its complex network: a possible therapeutic target in hematological diseases. Oncogene. 2011;30:2595-2609.

159. Holmberg Olausson K, Nistér M, Lindström MS. Loss of nucleolar histone chaperone NPM1 triggers rearrangement of heterochromatin and synergizes with a deficiency in DNA methyltransferase DNMT3A to drive ribosomal DNA transcription. J Biol Chem. 2014;289:34601-34619.

160. Saka K, Takahashi A, Sasaki M, Kobayashi T. More than $10 \%$ of yeast genes are related to genome stability and influence cellular senescence via rDNA maintenance. Nucleic Acids Res. 2016;44:4211-4221. 